\title{
APRENDIZAGEM DA ÁLGEBRA SEGUNDO RAYMOND DUVAL
}

\section{LEARNING ALGEBRA, ACCORDING TO RAYMOND DUVAL}

\author{
Celia Finck Brandt ${ }^{1}$ \\ Méricles Thadeu Moretti ${ }^{2}$
}

\begin{abstract}
Resumo: O artigo apresenta especificidades para o ensino da álgebra. Essas ideias contemplam uma abordagem cognitiva necessária para a aprendizagem da álgebra de acordo com Raymond Duval. Segundo o autor o ponto de vista cognitivo é incompatível com o ponto de vista matemático segundo o qual os objetivos globais são resolver equações e, para isso o importante é conhecer as letras. De acordo com o ponto de vista cognitivo o conhecimento das letras não é o objetivo principal. Para o autor a operação cognitiva de designação de objetos e relações é essencial. Também é preciso levar os alunos a elaborarem problemas, trabalhar com fórmulas, com tabelas de dupla entrada e com listas abertas para colocar em cena a função de condensação do padrão de regularidade na qual as letras entram para designar esse padrão. No texto são contemplados exemplos e dados empíricos resultantes de pesquisa desenvolvida pelos autores na aplicação das ideias em situações de ensino.
\end{abstract}

Palavras-chave: Aprendizagem da álgebra; Operações de designação; Abordagem semio-cognitiva.

\begin{abstract}
This article presents certain aspects for the teaching of algebra. The following ideas contemplate a cognitive approach, which is necessary for learning algebra, according to Duval. The author defends that the cognitive perspective is incompatible with the mathematical perspective, whose global objective is to solve equations; to achieve that goal, the important thing is to know the given letters. According to the cognitive point of view, the knowledge of letters is not the main objective. For the author, the cognitive operation of designating objects and relations is essential. One must also get students to work out problems and work with formulas, double-entry tables, and open lists, in order to prioritize the function of condensing the regularity pattern, in which the letters come in to designate exactly this pattern. In the article, there are examples and empirical data, resulting from a research developed by the authors in the application of ideas in teaching situations.
\end{abstract}

Keywords: Learning algebra; Designation operations; Semio-cognitive approach.

\section{Introdução}

A aprendizagem da álgebra pelos alunos na educação básica é fonte de dificuldades. Exemplo dessas dificuldades são erros recorrentes ao longo da escolaridade, tais como: $\mathrm{a}+\mathrm{b}=\mathrm{ab}$ ou $(\mathrm{a}+\mathrm{b})^{2}=\mathrm{a}^{2}+\mathrm{b}^{2}$; o não reconhecimento dos coeficientes de uma expressão analítica representativa de uma função no registro gráfico, dentre outros.

\footnotetext{
${ }^{1}$ Doutora em Educação Científica e Tecnológica pela UFSC. Pós-doutora pela UFSC. Professora do Curso de Licenciatura em Matemática da Universidade Estadual de Ponta Grossa (UEPG) e do Programa de Pós Graduação em Educação da UEPG e do Programa de Pós Graduação em Ensino de Ciências e Educação Matemática da Universidade Estadual de Ponta Grossa (UEPG), Ponta Grossa, Paraná, Brasil. Email: brandt@bighost.com.br

${ }^{2}$ Doutor em Educação Matemática pela Universidade Louis Pasteur (Estrasburgo I). Pós-doutor pela Universidade de Lisboa. Professor do Programa de Pós Graduação em Educação Científica e Tecnológica da Universidade Federal de Santa Catarina (UFSC), Florianópolis, Santa Catarina, Brasil. Email: mthmoretti@gmail.com
} 
Pesquisas $^{3}$ apontam que alguns desses erros são decorrentes da ideia de que o pensamento algébrico é uma extensão do pensamento aritmético. Essa ideia justificaria o erro apresentado pelos alunos de que $a+b=a b$, pois dois algarismos de um numeral justapostos são somados conforme o valor posicional no campo aritmético: $32=3 \times 10+$ 2. De igual maneira, explica logicamente que, se $2+3=5$, então $a+b$ tem que ser igual a algum valor, então $a+b=a b$. Se a álgebra for introduzida como extensão do pensamento aritmético será difícil aceitar que $a+b=a+b$.

Outras pesquisas também se voltam para a álgebra, seja seu ensino, a aprendizagem ou a formação de professores. A pesquisa de Ribeiro (2016) apresenta alguns resultados da pesquisa intitulada "Conhecimento Matemático para o Ensino de Álgebra: uma abordagem baseada em perfis conceituais" (OBEDUC/Capes), cujo objetivo geral foi investigar os conhecimentos algébricos desenvolvidos por professores de Álgebra na Educação Básica. A pesquisa buscou investigar se e como a abordagem de perfis conceituais pode contribuir para constituir e/ou ampliar os conhecimentos algébricos dos professores. A pesquisa foi desenvolvida por um grupo de professores que trabalhou com elaboração, desenvolvimento e análise de atividades matemáticas com diferentes significados de conceitos algébricos. O objetivo específico da pesquisa foi apresentar e discutir as múltiplas "vozes" da Educação Básica em torno das diferentes compreensões da Álgebra e de seu Ensino. Dentre os principais resultados, o autor apontou como essas diferentes compreensões podem "levar professores formadores e professores da escola básica a tomar essa importante área do conhecimento matemático 'apenas' como um amontoado de símbolos e procedimentos, na maior parte das vezes, desprovidos de significados" (p.1).

Outras reflexões sobre a álgebra podem ser encontradas na obra intitulada Álgebra para a formação do professor, de autoria de Ribeiro e Cury (2015). Nessa obra, os autores analisam resultados de pesquisas no campo da álgebra, em especial as pesquisas que se voltam para o ensino de equações e funções na perspectiva da formação do professor de matemática.

Os autores apresentam discussões sobre as dificuldades tanto dos alunos como dos professores, os quais apresentam uma concepção fortemente associada a procedimentos de resolução. Por essa razão os autores defendem a necessidade de estudos voltados para preencher as lacunas da formação dos professores, apontando, entre outras ações, a

\footnotetext{
${ }^{3}$ Os resultados dessas pesquisas são apresentados no livro: Shulte, A. P. \&Coxford, A. F. As ideias da álgebra. Editora Atual. 1995. Outros são apresentados no decorrer do texto.
} 
análise dos erros dos alunos como possibilidade para cursos de formação. Ao apontar a importância do aprendizado da álgebra na educação básica, ainda defendem que seu ensino pode ser proposto desde os anos iniciais. Os autores afirmam que diferentes concepções se projetam em atividades apresentadas em livros didáticos e também em documentos com orientações oficiais. Os autores destacam que muito se encontra a respeito do ensino de funções ou equações, mas que há poucos estudos voltados para a aprendizagem dos conceitos algébricos.

O livro de Ponte, Branco e Matos (2009), intitulado Álgebra no ensino básico, também constitui fonte importante de resultados de pesquisas sobre o ensino e a aprendizagem da álgebra, caracterizando um material de apoio ao trabalho dos professores. Os autores apontam diversos aspectos de caráter algébrico que podem ser trabalhados desde as séries iniciais do ensino fundamental: a exploração de sequências, o estabelecimento de relações entre números e entre números e operações e o estudo de propriedades geométricas, o desenvolvimento do pensamento algébrico dos alunos, entre outros. Os autores apresentam orientações gerais para o ensino da Álgebra, abordagens didáticas e o papel da tecnologia, tendo em vista o desenvolvimento do pensamento algébrico desde os primeiros anos de escolaridade. Para a apresentação de diversos tópicos de álgebra, são incluídos: discussões sobre conceitos fundamentais, aspectos específicos da aprendizagem dos respectivos conceitos, e exemplos e produções de alunos em tarefas específicas. Os Capítulos 4 e 5 abordam relações, sequências e regularidade. Especial atenção é dada ao ensino de relações e padrões de regularidade não valorizados no processo de ensino da álgebra. Os símbolos e as expressões algébricas são abordados em relação ao sentido a ser atribuído a eles e a formas de manipulação algébrica com significado relevante.

Já a pesquisa de Araújo, intitulada "Ensino de álgebra e formação de professores", apresenta reflexões sobre o pensar matemático e sobre a utilização da linguagem algébrica -segundo a autora, esses temas não são desenvolvidos apropriadamente nas salas de aulas. Com o objetivo de trazer contribuições para o ensino da álgebra, a autora apresenta um breve histórico do cenário atual do ensino da álgebra e, ao mesmo tempo, discute a problemática das diversas concepções da álgebra e o desenvolvimento do pensamento algébrico.

Sublinhamos também o estudo conduzido por Lemes e Cedro, intitulado "Profesores de las matemáticas enactividad de enseñanzadel álgebra: Apropiaciones de La teoría histórico-cultural", que aponta evidências sobra apropriações de conceitos 
algébricos de professores da educação básica em um curso de formação que os colocou frente a uma atividade de ensino, como se fossem alunos. Essa atividade foi fundamentada numa abordagem histórico cultural. Os principais resultados da pesquisa indicaram a importância de ações de formação que permitam que os professores possam inserir-se em um movimento de produção de sentido ao aprenderem e ensinarem álgebra.

O estudo apresentado neste artigo teve por finalidade a investigação das contribuições da Teoria das Representações Semióticas de Raymond Duval para a aprendizagem da álgebra. Presta-se igualmente à investigação de subsídios teóricos que permitem orientar o ensino para o desenvolvimento das habilidades e competências necessárias para a promoção do pensamento algébrico. O estudo buscou, também, compreender a natureza das ações a serem mobilizadas pelos alunos para a resolução de questões no campo algébrico, segundo um ponto de vista cognitivo. Nesse sentido, esse estudo se diferencia dos demais citados, por apresentar reflexões de natureza cognitiva em se tratando do desenvolvimento do pensamento algébrico, evidenciando assim um caminho para um ensino diferente da matemática. As contribuições do presente estudo para a aprendizagem de álgebra são embasadas nas ideias de Raymond Duval quanto à organização de atividades para o ensino.

Segundo Duval et al., (2015, p. 9), quando pensamos sobre o início do ensino da álgebra, e que progressão organizar para a proposta de atividades voltadas para a compreensão das escritas algébricas pelos alunos, somos levados a propor a decomposição de um complexo de conhecimentos, os quais diferenciam-se segundo um ponto de vista cognitivo ou matemático.

Este estudo procurará resposta para a seguinte questão: quais ideias apontadas por Raymond Duval são necessárias para o desenvolvimento do pensamento algébrico segundo um ponto de vista cognitivo? Como questões norteadoras: Quais as operações cognitivas necessárias para a atribuição de significação às escritas algébricas? Quais as diferenças entre o ponto de vista cognitivo e o ponto de vista matemático em se tratando da organização do ensino da álgebra?

Para a busca de respostas às questões levantadas, apontaremos as ideias defendidas por Raymond Duval para a construção de um pensamento geométrico de um ponto de vista cognitivo.

Adotamos como procedimentos metodológicos a apresentação das ideias de Raymond Duval apresentadas em uma palestra proferida por ele mesmo, “Deuxregardsopposessurles points critiques surl'enseignement de l'algèbreaucollège 
(11-15 ans)" no Programa de Pós-Graduação em Educação Matemática da Universidade Federal de Mato Grosso (em 2011b), além da apresentação de alguns exemplos: um grupo que se refere a respostas de alunos em questões propostas que fazem parte de uma pesquisa em desenvolvimento pelo GEPAM $^{4}$ (Grupo de Estudos e Pesquisas em Aprendizagem da Matemática) sobre a aprendizagem da álgebra e outro grupo com exemplos apresentados por Duval na palestra proferida. Também há exemplos que foram reformulados e adaptados para o presente artigo. As bases teóricas foram retiradas da palestra citada e da obra de Duval et al. (2015).

Diferentemente de outros objetos matemáticos, os objetos algébricos possuem especificidades próprias, que exigem abordagens metodológicas específicas para a condução do processo de ensino voltado para certas conceitualizações. Raymond Duval nos oferece reflexões relativas à aprendizagem da álgebra, as quais incluem, dentre outras, apontar as diferenças entre o ponto de vista cognitivo e o ponto de vista matemático, de modo a propor um currículo distribuído ao longo da escolaridade que se concretiza por meio do ensino e de diferentes atividades ou materiais didáticos.

Esse artigo propõe apontar as contribuições da Teoria das Representações Semióticas de Raymond Duval para a aprendizagem da álgebra. Temos por objetivos: apresentar bases teóricas para orientar um ensino voltado para o desenvolvimento de habilidades e competências necessárias para a promoção do pensamento algébrico; apontar, após reflexões analíticas, a natureza das ações a serem mobilizadas pelos alunos para a resolução de questões no campo algébrico.

\section{O Ponto de vista Cognitivo proposto por Duval}

Para a adoção de um ponto de vista cognitivo, será necessário evidenciar o que nos aponta Duval (2013) acerca da face oculta que compreende os gestos intelectuais, de natureza cognitiva e epistemológica, específicos em qualquer atividade matemática.

A face oculta considera o sentido, de acordo com Saussure (2008), e a referência, de acordo Frege (1971), de certas representações semióticas utilizadas para a representação de objetos algébricos em diferentes sistemas semióticos: língua natural, linguagem algébrica, linguagem numérica, linguagem gráfica, dentre outras. Esses dois elementos, sentido e referência, encontram-se presentes nas operações cognitivas de conversão de registros de representação de um sistema semiótico para outro, e de

\footnotetext{
${ }^{4}$ Cadastrado no diretório de grupos do CNPq.
} 
tratamento, a qual se volta para as transformações oriundas dos tratamentos dos registros de representação dos objetos algébricos realizados no interior de um mesmo sistema semiótico pelo sujeito que aprende. As conversões tratam das transformações dos registros de representação semióticos pertencentes a sistema semióticos diferentes e do tratamento dessas transformações no interior de um mesmo sistema semiótico. Conversões e tratamentos são operações cognitivas. Quando efetuamos transformações nos registros de representação, o sentido muda, mas não a referência. Por exemplo: as palavras e os numerais arábicos têm por referência um mesmo número, masveiculam de maneiras diferenciadas, e com sentidos diferentes, a estrutura do Sistema de Numeração Decimal Posicional. Na palavra, essa estrutura tem que ser identificada nos sufixos e prefixos, enquanto nos numerais trata-se da posição e do valor relativo dos algarismos.

Como exemplo, podemos citar também o conjunto dos números maiores que zero, que pode ser representado por "um número positivo" (em língua natural) ou "x $>0$ " (em linguagem algébrica). Diferentes sistemas semióticos são utilizados para expressar a mesma relação, mas exigem atribuição de significação em razão dos sentidos diferentes, ainda que tenham por referência o mesmo objeto algébrico.

A face oculta da atividade matemática tem que ser levada em consideração, visto que os objetos matemáticos não possuem existência real, o que exige muitos registros para acessá-los. Ela é essencial, também, pelo fato de que as atividades matemáticas apresentam especificidades, características que lhes são próprias, e que precisam ser consideradas tanto na organização dos currículos, como do ensino, de forma implícita. Essas especificidades são diferentes conforme os objetos matemáticos: algébricos, geométricos, aritméticos; ou conforme as ações: demonstrar, conjecturar.

A face oculta da atividade matemática não se encontra explicitada nos currículos e nem nos conteúdos distribuídos ao longo da escolaridade. Mas ela é importante, pois dará conta de propor um ensino da álgebra de um ponto de vista cognitivo. Segundo o ponto de vista cognitivo (DUVAL, 2013), os conceitos não constituem a parte mais importantes, mas sim os gestos intelectuais, pois eles permitem a conceitualização tendo por referência os objetos algébricos.

Outra questão essencial para a aprendizagem da álgebra, considerando um ensino conduzido de um ponto de vista cognitivo, se refere às funções discursivas e suas respectivas operações cognitivas. Isso porque os objetos algébricos utilizam os registros discursivos na língua natural, na linguagem numérica e na linguagem algébrica para serem representados. Os registros discursivos são utilizados primeiramente para 
representar relações operatórias entre números e letras (com o estatuto de variável, incógnita ou valor desconhecido); por essa razão, acabam por pertencerem ao que Yuri M. Lotman denomina de semiosfera, que se caracteriza num "espaço de encontro e de convivência dediversos sistemas semióticos e, igualmente, como [...] um espaço semiótico para a existência e funcionamento de linguagens, não asoma total das diferentes linguagens; em um certo sentido, a semiosfera tem uma existência prévia e está em constante interação com as linguagens" (LOTMAM, 1990, p.123).

Tais sistemas semióticos têm características marcantes de heterogeneidade. A heterogeneidade é definida tanto pela diversidade de elementos quanto por suas diferentes funções. Merrell (2003, p. 166-169) classifica a heterogeneidade dos sistemas semióticos em Lotman (1990) no estágio da terceira tricotomia, ou seja, no terceiro componente do signo, o interpretante, um nível de categorias mais evoluída dos signos em Charles $\mathrm{S}$. Peirce. Lotman (1990, p. 127) considera que, quanto mais heterogêneos são os sistemas integrados, mais promissoras são as possibilidades de ganho de informação.

A representação das relações operatórias entre números e letras exige funções discursivas e suas respectivas operações cognitivas; dentre elas, destaca-se a operação de designação da função referencial (DUVAL, 2004). Esse ato de designar caracteriza no terreno algébrico, mais especificamente, uma semiosfera da designação.

Várias atividades podem ser elaboradas para contribuir à construção de uma semiosfera da designação para a aprendizagem da álgebra. A designação é uma das funções dos registros discursivos e só pode ser realizada por meio de suas operações cognitivas: categorização pura, categorização simples, determinação e descrição (por meio de léxicos associativos ou sistemáticos). Essa designação é acompanhada da função apofântica (de enunciados completos e suas respectivas operações cognitivas de predicação e elocução), da função de expansão discursiva (possibilitada pela composição de enunciados e suas operações cognitivas de descrição, narração, explicação e raciocínio) e da função de reflexividade discursiva (por meio de leis ou propriedades válidas do ponto de vista epistêmico).

Como exemplo ${ }^{5}$, podemos citar uma sequência numérica a ser completada e designada por uma sentença matemática: 1, 4, 7, 10, 13, 19,... Para completar a sentença,

\footnotetext{
${ }^{5}$ Esses dados empíricos foram obtidos a partir da aplicação de um instrumento com questões de álgebra a alunos do 8o ano do Ensino Fundamental de escolas públicas da rede estadual de ensino de uma cidade do Paraná. Visando preservar a identidade dos respondentes, cada turma foi marcada por uma letra (A, B, C, D e E) e cada aluno da turma foi designado por um número $(\mathrm{A} 1, \mathrm{~A} 2, \ldots, \mathrm{B} 1, \mathrm{~B} 2, \ldots, \mathrm{C} 1, \mathrm{C} 2, \ldots, \mathrm{D} 1, \mathrm{D} 2, \ldots$, etc.).A questão proposta era a seguinte: Questão 1 - Escreva uma sentença matemática que represente a sequência 1, 4, 7, 10,
} 
os alunos podem utilizar a linguagem numérica com léxicos sistemáticos $22,25,28, \ldots$ (resposta do aluno D3) ou associativos e sistemáticos combinados:

\begin{tabular}{ccccccccc}
$x$ & $x$ & $x$ & $x$ & & 1 & 4 & 7 & 10 \\
+3 & +6 & +9 & +12 & $\mathrm{Ou}$ & $+x$ & $+x$ & $+x$ & $+x$ \\
4 & 7 & 10 & 13 & & 4 & 7 & 10 & 13 \\
\multicolumn{3}{l}{ Resposta do aluno A5 } & & \multicolumn{3}{c}{ Resposta do aluno C19 }
\end{tabular}

A designação do padrão de regularidade, por meio de um enunciado completo (função apofântica) "vai de 3 em 3” (resposta do aluno C8 em língua natural e numérica), permite inferir o que não está explicitado, isto é, que esse padrão não é de natureza operatória, pois se baseia na sequência numérica. Essas inferências são possibilitadas pela função de expansão discursiva e suas respectivas operações cognitivas de narração, explicação, descrição ou raciocínio. Diferentemente, o enunciado "soma 3" (resposta do aluno A9) permite inferir que esse padrão é de natureza operatória; ou ainda a enunciação “pula 2" (resposta do aluno C7), também não é operatório, pois se baseia na sequência. O padrão de regularidade também pode ser designado por meio de uma sentença matemática na linguagem algébrica: $\mathrm{y}=\mathrm{x}+3$ (resposta do aluno $\mathrm{C} 2$ ) ou $\mathrm{y}-\mathrm{x}=3$ (resposta do aluno D12), ambas de natureza operatória.

Esses enunciados fazem entrar em cena o ato ilocutório (operação cognitiva da função apofântica): o aluno falando ao professor (logo no estágio da terceiridade), que então interpreta a respostas apresentadas pelos alunos.

Para a designação do padrão de regularidade, é preciso identificaras características de natureza qualitativa da sequência.

Diferentes sistemas semióticos discursivos combinam-se para formar um novo espaço, caracterizando a semiosfera da designação essencial para a aprendizagem da álgebra. Essa designação dos padrões de regularidade, de diferentes formas, permite as apreensões necessárias para o desenvolvimento do pensamento algébrico, que não se caracteriza como uma extensão do pensamento aritmético. Elas têm que ser contempladas em um ensino da álgebra que leve em conta o ponto de vista cognitivo.

Para levar em conta, no ensino, a semiosfera da designação, é importante definir num primeiro momento a diferença entre signo e representações semióticas. Uma

$13,16, \ldots$ e complete com os próximos 5 números. Mas atenção, não basta indicar os números que completam a sequência, é necessário demonstrar como conseguiu encontrá-los, usando sentenças matemáticas. 
exemplificação simples e resumida sobre essa diferenciação (Duval, 2011a) consiste em entender que as representações semióticas são as frases em linguagem natural, as equações, e não as palavras, os algarismos e as letras. São as figuras, os esquemas, os gráficos, e não os pontos, raramente visíveis, ou os traços. Muitas vezes associamos os signos a essas unidades elementares de sentido, que são apenas caracteres para codificar: letras, siglas, algarismos, às vezes palavras-chave, ou os gestos da mão. O que equivale a considerar os signos como as "coisas" pelas quais é preciso começar para dar um sentido (DUVAL, 2011a, p. 38).

Para que possamos prosseguir, é necessário que sejam levantados e respondidos alguns questionamentos de ordem epistemológica e cognitiva: O que é o conhecimento matemático? O que ele pode ter de diferente dos outros tipos de conhecimento? Temos um acesso direto e imediato aos objetos matemáticos? Para confirmar o que foi comentado anteriormente sobre a inexistência física dos conceitos matemáticos, Duval (2011a) afirma que as "boas" representações não se associam direta ou empiricamente ao objeto matemático que representam, pois não são acessíveis. A única possibilidade de acesso a esses objetos se dá pela correspondência que se faz entre os diferentes tipos de representação. $\mathrm{O}$ autor complementa que os encaminhamentos científicos, em outras áreas do conhecimento, como física, astronomia e biologia, se dão de formas radicalmente distintas do encaminhamento matemático, que "consiste em transformações de representações semióticas, dadas ou obtidas no contexto de um problema proposto, em outras representações semióticas." (DUVAL, 2011a, p. 52). Assim, segundo este mesmo autor, o conhecimento deve considerar:

- a natureza dos objetos, a forma como são apresentados e como podemos ter acesso a eles por nós mesmos, assim como os processos cognitivos mobilizados em qualquer ação do pensamento matemático;

- os sistemas, estruturas ou capacidades do sujeito necessárias ou mobilizadas para que tenhamos acesso aos objetos, diretamente ou por uma sequência de processos conscientes ou não conscientes;

- a natureza da relação cognitiva entre os processos e os objetos. 


\section{O Ensino de Álgebra na Perspectiva dos Registros de Representação Semiótica}

Em se tratando do conhecimento algébrico, a semiosfera da designação é uma exigência. No ensino, ela pode ser contemplada na operação cognitivade conversão, que permitirá ao professor propor ao aluno a análise e a descrição da atividade matemática.

Essa operação cognitiva vai exigir: colocar em correspondência as unidades de sentido de duas representações semióticas de naturezas diferentes, que representam o mesmo objeto; identificar as unidades de sentido de cada uma das representações; distinguir, em uma transformação, a transformação de partida e a de chegada.

Podemos citar como exemplo uma função linear expressa pela sentença matemática $\mathrm{y}=\mathrm{ax}+\mathrm{b}$. As variações podem contemplar os coeficientes a e b e a antecipação das transformações nos diferentes gráficos representativos dessas funções. $\mathrm{O}$ mesmo objeto algébrico deve ser enxergado nessas diferentes representações. No caso em questão, a variação do coeficiente a incidirá no ângulo formado entre a reta e o eixo das abscissas e na determinação da reta, se crescente ou decrescente $(f(x)>y$ ou $f(x)<y)$, além da variação do coeficiente b na intersecção da reta com o eixo das ordenadas acima ou abaixo de zero.

Outro exemplo a ser citado é a proposta de Moretti (2003), ao transportar o estudo de Raymond Duval sobre o esboço de curvas, realizado para o caso das retas, para outras curvas - no caso, as parábolas. Ao realizar uma investigação específica sobre o tema, Moretti (2003) aponta a utilização da translação para coordenar as operações cognitivas de conversões, nos dois sentidos, entre gráfico e equação. Outro aspecto apontado por Moretti (2003) refere-se ao fato de que tal abordagem contribui para que o aluno perceba o lugar geométrico de pontos no plano como uma imagem que representa um objeto descrito por uma expressão algébrica.

A representação da função $y=a x+b$ no plano cartesiano caracteriza uma atividade de conversão; como apontando anteriormente, o procedimento por pontos não especifica a ligação existente entre o gráfico e a expressão algébrica correspondente. Há congruência no sentido do par ordenado ao ponto do plano, mas não o inverso. Será importante considerar o procedimento de interpretação global das propriedades figurais. O traçado é um lugar geométrico de pontos representativos de uma expressão algébrica. As variações das unidades significativas da expressão algébrica deverão ser associadas às variações da curva. 
Para a proposta desse procedimento, devem ser identificadas as unidades significativas na linguagem algébrica, para associação da variação do gráfico. No caso de funções do primeiro e do segundo grau, essas unidades referem-se aos coeficientes.

$$
\begin{gathered}
y=a x+b ; y=a_{1} x+b ; y=a x+c \\
y=a x^{2} ; y=a x^{2}+b ; y=a x^{2}+b x ; y=a x^{2}+b x+c ; y=a x^{2}+c
\end{gathered}
$$

Essas variações na linguagem algébrica permitem associações imediatas com as variações visuais na representação gráfica. Moretti (2003) nos apresenta uma abordagem que leva em conta as transformações geométricas, especialmente a translação, que contribui de forma significativa para essas associações, permitindoo estabelecimento de uma correspondência entre gráfico e expressão algébrica de forma coordenada e em ambos os sentidos.

A parábola $y=a x^{2}+b x+c$ pode ser interpretada como uma translação de $y=a x^{2}$ , pois $y=a x^{2}+b x+c$ pode ser transformada utilizando o método de completar de quadrados:

$$
\begin{gathered}
\frac{y}{a}=x^{2}+\frac{b x}{a}+\frac{c}{a} \\
\frac{y}{a}=x^{2}+\frac{b x}{a}+\frac{c}{a}+\frac{b^{2}}{4 a^{2}}-\frac{b^{2}}{4 a^{2}} \\
\frac{y}{a}+\frac{b^{2}}{4 a^{2}}-\frac{c}{a}=x^{2}+\frac{b x}{a}+\frac{b^{2}}{4 a^{2}} \Rightarrow \frac{y}{a}+\frac{b^{2}}{4 a^{2}}-\frac{c}{a}=\left(x+\frac{b}{2 a}\right)^{2} \\
\underbrace{\frac{b^{2}}{4 a}-c}_{\begin{array}{c}
\text { Deslocamente } \\
\text { vertical }
\end{array}}=\underbrace{a\left(x+\frac{b}{2 a}\right)^{2}}_{\begin{array}{c}
\text { Deslocamento } \\
\text { horizontal }
\end{array}} \Rightarrow y+\underbrace{\frac{b^{2}-4 a c}{4 a}}_{\begin{array}{c}
\text { Deslocamente } \\
\text { vertical }
\end{array}}=\underbrace{a\left(x+\frac{b}{2 a}\right)^{2}}_{\begin{array}{c}
\text { Deslocamento } \\
\text { horizontal }
\end{array}}
\end{gathered}
$$

Os valores dos deslocamentos vertical e horizontal corresponderão às coordenadas do vértice da nova parábola. Cada ponto da parábola sofrerá a mesma alteração para os valores da abscissa e ordenada.

Dada a função $y=2 x^{2}-8 x-10$. Completando o quadrado, temos:

$$
y=2 x^{2}-8 x-10 \Rightarrow y=2\left(x^{2}-4 x-5\right) \Rightarrow y=2\left(x^{2}-4 x+4-4-5\right) \Rightarrow y=2\left[(x-2)^{2}-9\right]
$$

ou $y+18=2(x-2)^{2}$, sendo que o vértice dessa parábola tem coordenadas $(2,-18)$, ou seja, em relação à parábola $y=2 x^{2}$, o deslocamento vertical é de 18 unidades e o deslocamento horizontal é de 2 unidades. 
Qualquer ponto da curva sofrerá essa transformação. Por exemplo, o ponto de coordenadas $(1,2)$ pertencente à parábola representada pela sentença $y=2 x^{2}$ corresponde ao ponto $(3,-16)$ na parábola representada pela sentença $y=2 x^{2}-8 x-10$.

$\mathrm{Na}$ introdução e utilização de letras no ensino da álgebra, as maiores dificuldades são: resolução de equações e resolução de problemas. Segundo Duval (2011b), o ensino, do ponto de vista matemático, está organizado da seguinte maneira:

1) Definição dos conhecimentos globais a serem adquiridos ao final de um ciclo de ensino e dos objetivos finais do ensino da álgebra. Esses conhecimentos são estabelecidos pelos matemáticos, pelos didáticos, pelos professores da educação e pelas políticas ministeriais.

2) Definição da decomposição a ser feita com os elementos de base que apontam que tarefa propor, que definições propor e que problemas dar, visando um desses elementos de base;

3) Definição da progressão organizada (sobre um ano, um ciclo) para adquirir um desses elementos de base. Considerada a etapa mais importante, pois vai decidir a progressão que será feita em um ano, dois anos, cabendo aos professores e aos psicólogos pensar como fazer e o que fazer para atingir esses objetivos. Esta organização está esquematizada na Figura 1:

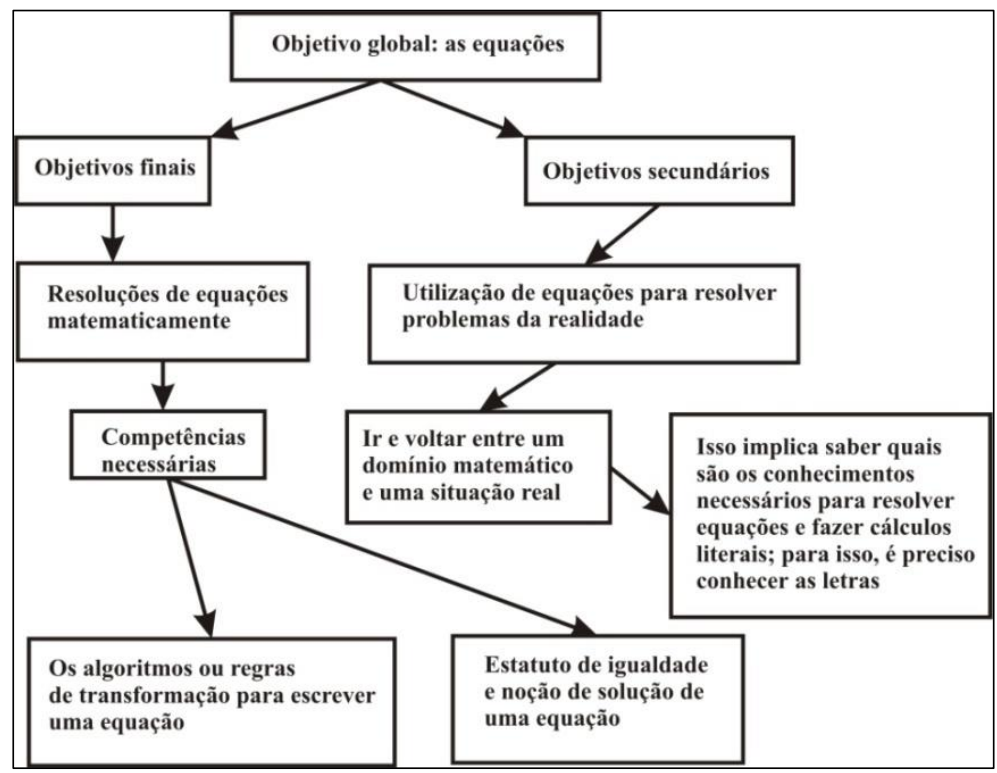

Figura 1: Esquema da organização do ensino da álgebra segundo um ponto de vista matemático

Fonte: Os autores a partir da palestra de Duval proferida em Campo Grande.

Essa forma de organização está assentada, segundo Duval et al. (2015) em uma análise regressiva, segundo a qual se propõe a organização do ensino em ciclos ou em um 
ano. Essa organização se refere ao ensino das equações, e está pautada em uma decomposição regressiva, implicando na escolha dos exercícios e dos problemas a propor no ensino (DUVAL et al., 2015, p. 19-20). O autor ressalta, no entanto, que:

\begin{abstract}
Quase todas as pesquisas sobre o ensino da matemática se fazem no quadro da decomposição regressiva dos conhecimentos a adquirir, mas sem jamais tentar superá-lo. Assim não nos interrogamos sobre a possibilidade de outro ponto de vista que não parta de conhecimentos completos a ensinar, mas sobre a maneira como temos acesso aos objetos matemáticos e como trabalhamos a matemática sobre esses objetos ou com eles. A decomposição de outros pontos de vista, em razão das dificuldades encontradas pelos alunos [...]. Essa decomposição regressiva é identificada do ponto de vista matemático e a consideração de outros pontos de vista é total e localmente a ele subordinada (DUVAL et al., 2015, p.20).
\end{abstract}

Duval (2011b) entende que um caminho inverso pode ser proposto: é preciso primeiro levar os alunos a conhecer as letras, colocá-las em equação, e depois começar a trabalhar com as ideias de igualdade e desigualdade. Duval (2011b) defende um outro ponto de vista, o cognitivo, que definirá a decomposição dos objetivos para a aquisição dos conceitos algébricos. Esse ponto de vista compreende cinco ideias que devem ser levadas em consideração.

Do ponto de vista cognitivo, o ensino:

- Não deve focalizar imediatamente sobre os saberes a adquirir, mas sobre o funcionamento cognitivo necessário para que os alunos possam compreender e fazer o trabalho solicitado para, portanto, aprender. Ele deve ter por centro a atividade intelectual necessária, ato de pensamento, sem o qual os conhecimentos não podem emergir.

- Deve-se voltar para a decomposição de operações cognitivas em função dos sistemas semióticos mobilizados. Essas operações cognitivas são de natureza discursiva e, em específico, em função de designação. Para tanto, é necessário levar em conta os tipos de signos e de produções que serão exigidos. Diferentes operações discursivas emergirão conforme os sistemas semióticos em uso (a língua natural, a linguagem numérica, a linguagem algébrica). Os tipos de signos poderão ser palavras, números ou letras e símbolos. A operação discursiva de designação permitirá designar todo tipo de objeto por palavras, permite designar os números e as operações, além de designações para apontar os cálculos e para utilizar algoritmos.

Duval et al., (2015) ressalta, no entanto, que existem dificuldades associadas à utilização das letras para as operações de designação. Em relação às letras, a dificuldade está associada à seguinte questão: porque devo utilizar letras se posso utilizar números? Essa questão tem a ver com uma "ruptura epistemológica entre álgebra e aritmética" 
(GRUGEON ${ }^{6}, 1977$ apud DUVAL et al., 2015, p. 29). Outra questão diz respeito à dificuldade de utilizar uma letra para exprimir uma relação entre dois números dados (DUVAL et al., 2015, p.30). O autor, ao se referir ao problema de um retângulo com perímetro de $920 \mathrm{~m}$ e comprimento de $20 \mathrm{~m}$ a mais que a largura, aponta que os alunos designam a relação $920=2 \mathrm{C}+2 \mathrm{~L}$, mas não conseguem designar a relação entre $\mathrm{C}$ e $\mathrm{L}$ como $\mathrm{C}=\mathrm{L}+20$. Essa ação cognitiva exige uma dupla designação, conforme Duval (2011b) apontou em sua palestra. Também há dificuldade em designar a articulação de igualdades numéricas com várias operações, as igualdades que exigem a utilização de parênteses, como por exemplo $\mathrm{a}+\mathrm{a}+\mathrm{a}+2=3 \mathrm{a}+2 \mathrm{e} \mathrm{a}+\mathrm{a}+\mathrm{a} \times 2 \neq 3 \mathrm{a} \times 2$, ou a designação funcional de relações entre variáveis (p. 31). Outra dificuldade diz respeito à designação de uma grandeza, que é confundida com a designação de um objeto. O autor cita como exemplo o preço de um livro representado por $\mathrm{L}$.

Duval (2011b) defende cinco ideias a serem contempladas no ensino da álgebra a partir de um ponto de vista cognitivo. Para que dar início à discussão sobre essas ideias, é necessário destacar a semiosfera da designação. Duval (2011b) pondera sobre a fragilidade do discurso em relação à produção escrita. Afirma que a produção escrita exige um cuidado maior no controle das operações discursivas, o que não acontece na maioria das situações de fala espontânea, circunstâncias em que a complexidade da designação de objetos é ignorada.

De acordo com Duval (2011b), não são as letras que são importantes, mas as operações discursivas de designação dos objetos, que são feitas por meio da língua natural ou formal (primeira ideia). É a semiosfera da designação que é exigida. Em relação às práticas espontâneas de designação dos objetos, a álgebra exige que utilizemos, de imediato, outro tipo de designação. Os objetos que precisaremos designar são quantidades, números, grandezas ou listas abertas de números que podem ter uma relação entre si. Vejamos um exemplo. Sejam as listas:

\begin{tabular}{|l|l|l|l|}
\hline 1 & 2 & 3 & 4 \\
\hline 2 & 3 & 4 & 5 \\
\hline
\end{tabular}

Para a designação do padrão de regularidade que une essas duas listas, podemos escrever em língua natural que “cada número da lista debaixo é igual ao número da lista

6 GRUGEON, B. Conception et exploitation d'une structure d'analyse multidimensionelleem algèbre élémentaire. Revue de Didactiquedes Mathématiques, v. 17, n.2, 1977. 
de cima mais uma unidade". Se perguntarmos ao aluno o que acontecerá para qualquer número da lista, será necessária uma designação das relações existentes por meio de letras, números e operações: $\mathrm{x}=\mathrm{y}+1$.

A semiosfera da designação contemplará a maior parte das relações existentes no campo algébrico. Essas designações não são de mesma natureza, podendo ser: designação verbal, designação numérica, designação indireta (descritiva ou funcional), dupla designação, designação direta, dentre outras. O exemplo a seguir explicita os diferentes tipos de designação: "Rita e Carlos têm juntos 54 anos. Rita tem oito anos a mais que Carlos. Quantos anos tem Carlos? Quantos anos tem Rita?"

Nesse caso, as designações necessárias se dão conforme a descrição do Quadro 1.

\begin{tabular}{|c|c|c|c|}
\hline & $\begin{array}{c}\text { Designação verbal } \\
\text { (usando a língua } \\
\text { natural) }\end{array}$ & Dados numéricos & $\begin{array}{c}\text { Redesignação verbal } \\
\text { (usando a linguagem } \\
\text { algébrica) }\end{array}$ \\
\hline Designação direta & $\begin{array}{c}\text { Idade de Rita mais } \\
\text { idade de Carlos igual a } \\
54\end{array}$ & 54 & $\begin{array}{c}\mathrm{x}+\mathrm{y}=54 \\
\mathrm{x} \text { representa a idade de Rita } \\
\mathrm{y} \text { representa a idade de } \\
\text { Carlos }\end{array}$ \\
\hline $\begin{array}{l}\text { Designação indireta: } \\
\text { descritiva ou } \\
\text { funcional }\end{array}$ & $\begin{array}{c}\text { Rita tem } 8 \text { a mais que } \\
\text { Carlos }\end{array}$ & $\begin{array}{c}+8 \text { (uma } \\
\text { designação } \\
\text { numérica relativa } \\
\text { à idade de Rita) }\end{array}$ & $\mathrm{x}($ Rita $)=\mathrm{y}($ Carlos $)+8$ \\
\hline $\begin{array}{l}\text { Dupla designação } \\
\text { de um mesmo objeto }\end{array}$ & Idade dos dois juntos 54 & $\begin{array}{c}\text { 54: designação } \\
\text { direta (designação } \\
\text { relativa à idade } \\
\text { dos dois juntos) e } \\
\text { 8: designação } \\
\text { indireta (ou } \\
\text { funcional) (a } \\
\text { idade de Rita em } \\
\text { função da idade de } \\
\text { Carlos) }\end{array}$ & $(y+8)+y=54$ \\
\hline
\end{tabular}

Quadro 1: Designações de relações algébricas

Fonte: os autores

Duval (2011b) nos aponta que existe uma complexidade cognitiva para nomear ou designar qualquer coisa, pois não existem palavras que permitam, por vezes, designar alguns objetos. Isso acontece porque: todos os objetos não são da mesma natureza, para que assim sejam nomeados (indivíduos, classes, incógnitas etc.); há operações ou maneiras de nomear que são diferentes segundo a natureza dos objetos designados; cada sistema tende a privilegiar uma operação sobre as outras.

Duval (2011b) nos apresenta as formas para as operações de designação. Elas podem ser diretas, com palavras de uma língua para nomes próprios, substantivos, tempo, entre outros, ou com letras ou simbolos para variáveis, valores desconhecidos, 
parâmetros, incógnitas. Elas podem ser construídas por combinação de muitos termos, como por exemplo "a idade de Rita", ou por meio de expressões, como por exemplo "d/v", para designar o tempo gasto por um carro em determinada velocidade e em uma distância específica. Há ainda a comparação a um objeto de ancoragem, por exemplo, um objeto designado em função de outro " $\mathrm{y}=\mathrm{x}+8$ " no exemplo do problema de Rita e Carlos.

Duval (2011b) ressalta ainda que há duas exigências cognitivas incontornáveis:

- A escolha da incógnita (uma aparente designação direta) recobre operações de designação construídas de formas diferentes conforme o problema a ser resolvido. Por exemplo, no caso do problema de Rita e Carlos, são três designações: a idade de Rita por uma letra "x", a idade de Carlos por uma letra " $y$ ”, e a redesignação da idade de Rita em função da idade de Carlos “ $\mathrm{x}=\mathrm{y}+8$ ".

- Estabelecer uma equação exige que se isole duas designações diferentes do mesmo objeto, isto é, que se encontre uma equivalência de duas expressões (FREGE, 1971). No problema de Rita e Carlos, teríamos: se $\mathrm{x}+\mathrm{y}=54$ e se $\mathrm{x}=\mathrm{y}+8$, então $\mathrm{y}+8+\mathrm{y}$ =54. Dito de outra forma, se de um ponto de vista matemático a existência de simétricos (oposto e inverso) permite justificar a mudança de lado para a resolução da equação que se estabelece, é esta dupla designação, por equivalência semântica, que permite compreender e estabelecer a equação e seu funcionamento. Assim: se x $+\mathrm{y}=54$, se $\mathrm{x}=\mathrm{y}+8$, então $\mathrm{y}+8+\mathrm{y}=54$ (equivalência semântica obtida por substituição).

Essas mesmas exigências encontram-se nos enunciados dos problemas para os quais a álgebra oferece uma ferramenta útil de resolução. Isso significa, segundo Duval (2011b), que o reconhecimento e a produção de duas designações de um mesmo objeto é uma prática estranha às práticas espontâneas da língua em torno da matemática. Neste exemplo, o problema do reconhecimento é colocado pela congruência entre proposição e equação (as duas designações estão numa mesma frase). Em função dessas questões, Duval (2011b) nos aponta o que fazer para levar em conta, no ensino, a importância da operação de designação. Primeiro, é necessário que os professores tomem consciência dos problemas oriundos da designação na língua natural e da necessidade de designações construídas por condensação (por exemplo, generalizar a relação existente entre os números de duas listas: $\mathrm{y}=\mathrm{x}+1$; isto é, qualquer número da segunda lista pode ser obtido somando uma unidade aos seu correspondente em uma primeira lista) e por combinação ou substituição (por exemplo: $\mathrm{x}=\mathrm{y}+3 ; \mathrm{z}=\mathrm{y}+5 ; \mathrm{x}+\mathrm{z}=\mathrm{y}+5+\mathrm{y}+3$ ). É preciso 
também que os professores tomem consciência da necessidade das designações construídas por condensação sobre os dados numéricos (no caso de listas abertas e da designação do padrão de regularidade que liga os números de uma lista em função de outra). Essa condensação ocorre em virtude da identificação de um padrão de regularidade.

Outra questão diz respeito à introdução das letras, que é feita para designar não somente um objeto, mas muitos objetos diferentes. Essa questão refere-se às diferentes operações cognitivas próprias da função de designação: designação pura (por meio de léxicos sistemáticos), categorização simples, por meio de léxicos associativos, determinação e descrição. Podemos exemplificar: "Sejam A, B e C os vértices de um triângulo", ou sejam “A, B e C os pontos médios de três segmentos”. A introdução de uma letra não se faz para designar um objeto, mas para oferecer os meios de designação de muitos objetos diferentes (é o caso das mesmas letras, A, B e C, usadas para designar ora vértices e ora pontos médios).

Outra questão apontada por Duval (2011b), também com relação à operação de designação, é não propor situações de instanciação, mas sim listas abertas de números que acabarão por exigir uma letra para a designação do padrão de regularidade com utilização de uma sentença matemática. Os professores, no ensino da álgebra, devem propor situações que levem os alunos a identificar a referência ao mesmo objeto, após transformações ou conversões entre sistemas semióticos diferentes. Por exemplo: "um número somado a três resulta em oito" tem por referência o mesmo objeto da sentença " $\mathrm{x}$ $+3=8$ ". Essa equivalência referencial tem que ser contemplada no ensino. Ela diz respeito à face oculta da matemática e é fundamental para a aprendizagem da álgebra.

Outra questão apontada por Duval (2011b) diz respeito à noção de equação com sua possibilidade própria de transformação por mudança de lado com vistas à resolução. Essa ação tem que ser percebida pelos alunos como uma forma de expressar uma mesma quantidade de duas maneiras - a isto se nomeia equação. Novamente, a equivalência referencial e a utilização dos princípios aditivo e multiplicativo servem para sustentar essa transformação. Exemplo:

$$
x+3=8 \therefore x=8-3 \text {, pois } x+3-3=8-3 \text { (princípio aditivo). }
$$

Outro exemplo pode ser visualizado no Quadro 2. 
Outro exemplo: A balança a seguir só ficou equilibrada quando foi colocado o sexto cubo no prato direito.

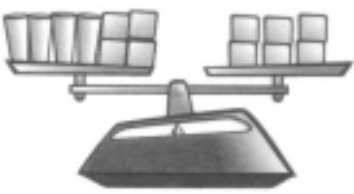

Sabendo que cada cubo tem massa igual a 40 gramas, qual é a massa de cada copo?

Quadro 2: Problema de álgebra

Fonte: os autores

As designações de relações entre as massas dos objetos (copos e cubos) dos dois pratos da balança, e tambéma relação de igualdade representativa do equilíbrio, poderão ser analisadas conforme o Quadro 3:

\begin{tabular}{|c|c|c|c|}
\hline & Designação verbal & Dados numéricos & $\begin{array}{l}\text { Redesignação verbal } \\
\text { com utilização de letras }\end{array}$ \\
\hline & $\begin{array}{l}\text { Massa dos cubos do prato } \\
\text { do lado esquerdo e direito } \\
\text { da balança }\end{array}$ & 40 & $\begin{array}{l}\text { 4a e } 6^{\mathrm{a}}, \text { sendo “a” uma } \\
\text { redesignação da massa } \\
\text { dos cubos }\end{array}$ \\
\hline $\begin{array}{lr}\text { Designação } & \text { indireta: } \\
\text { descritiva } & \text { ou } \\
\text { funcional } & \end{array}$ & $\begin{array}{l}\text { A massa dos copos e } \\
\text { cubos do lado esquerdo é } \\
\text { igual à massa dos cubos } \\
\text { do prato do lado direito }\end{array}$ & $\begin{array}{c}4 \times 40+4 \ldots . .=6 \times 40 \\
\text { designação numérica } \\
\text { relativa à igualdade } \\
\text { representativa do } \\
\text { equilíbrio da balança }\end{array}$ & $160+4 b=240$ \\
\hline $\begin{array}{l}\text { Dupla designação de } \\
\text { um mesmo objeto }\end{array}$ & A massa dos copos & $240-160=80$ & $6 a-4 a=4 b$ \\
\hline
\end{tabular}

Quadro 3: Designações de relações algébricas

Fonte: os autores

No quadro acima, é possível visualizar as diferentes formas de designação das relações em linguagem natural, numérica e algébrica. No momento da designação indireta e descritiva, é possível atribuir significado à letra para representar a massa dos copos. No momento da dupla designação, é possível visualizar a massa dos copos em função da massa dos cubos.

Por meio desses exemplos, é possível explicitar que as operações semiocognitivas de designação não são tão evidentes e espontâneas, pois precisam ser objeto do ensino para a atribuição de sentido e significação no interior das próprias relações. Esclarecemos essa ideia representando as relações entre os objetos dos pratos da balança, feitas pelo aluno C9 da pesquisa já citada, na forma: $4+4 b=6$. Nessa designação, $b$ representa o número de copos e seu valor estabelece a relação entre a massa de um objeto e um copo, isto é, dois copos representam um objeto ou um copo tem metade da massa 
de um objeto. Nesse caso, um mesmo léxico associativo ora pode representar a massa do objeto e ora pode representar o número de objetos de determinada natureza.

Segundo Duval (2011b), para compreender o funcionamento quanto à forma de estabelecer uma equação, não devemos propor a resolução de problemas, mas sim a elaboração de problemas (segunda ideia). É necessário que os alunos aprendam a fazer problemas, mas isso não pode ser feito de qualquer maneira, pois será necessário realizar variações e supressões. Há diversas maneiras de suprimir os dados de um problema para que os dados restantes permitam encontrá-los. Exemplo: dois mais três é igual a cinco. Temos cinco dados: $2,+, 3,=, 5$. Podemos suprimir,$+=$ (uma primeira variação) e elaborar um problema com os números 2, 3 e 5. Exemplo de problema a ser elaborado: dois multiplicado por três é maior que cinco $(2 \times 3>5)$. Mas podemos fazer outra variação: por exemplo, suprimindo o 2 e ficando com os números 3 e 5, com a relação de igualdade e com a operação de adição. Nesse caso, existem diversas possibilidades para compor enunciados concretos. Por exemplo:

- Tenho 5 balas e como 3 , com quantas fico? $(5-3=\ldots$.

$\mathrm{Ou}$

- Tenho algumas flores, e ganhei de presente 3 da minha amiga. No final fiquei com 5. Quantas flores tenho? $\quad(\ldots+3=5)$

$\mathrm{Ou}$

- Tinha 3 balas e ganhei algumas ficando com 5. Quantas balas ganhei? (3+ $\ldots=5)$

Essas variações e supressões dizem respeito à análise cognitiva do problema. Para o exemplo do problema, da idade acima apresentado (idade de Rita e Carlos), as variações poderiam ser:

\section{A idade de Carlos e Rita somam 54. Rita tem 8 anos a mais que Carlos.}

Há três maneiras de suprimir os dados; como consequência, três problemas podem ser elaborados. A forma de propor o procedimento é perguntar: se eu suprimir um dos dados, como posso encontrar o outro? Quantas supressões diferentes eu posso fazer?

- $23+\ldots=54$ (Carlos tem 23 anos. A idade de Rita e Carlos somam 54. Quantos anos tem Rita?); Nesse caso, a idade de Carlos foi revelada e, por essa razão, a designação desaparece, pois a partir da soma da idade dos dois é possível obter a idade de Rita. A supressão do valor desconhecido (idade 
de Carlos) implica na supressão da idade de Rita, em função da idade de Carlos, visto que pode ser obtida de modo direto.

- $\quad \ldots+31=54$ (Carlos tem certa idade e Rita tem 31 anos. A idade dos dois juntos é 54 anos. Quantos anos tem Carlos?);

- $23+31=\ldots$ (Rita tem 31 anos e Carlos tem 23 anos. Quantos anos têm os dois juntos?)

Duas situações equivalentes são possíveis: a supressão exige uma designação funcional, que é a descrição de uma operação a ser feita. A primeira designação é relativa a esse enunciado: Rita tem 8 anos a mais que Carlos. Essa supressão introduz outro dado que não está presente na designação funcional na qual foram suprimidos os dois dados.

Segundo Duval et al., (2015, p. 68-69), a elaboração de problemas pelos alunos apresenta uma vantagem didática considerável, visto que duas condições se tornam essenciais: "oferece o meio de comparar imediatamente as diferentes maneiras pelas quais se pode representar matematicamente um problema." e "precisamos trabalhar sobre as diferentes maneiras que os termos de uma operação podem corresponder a dados reais. [...] a designação verbal dos dados numéricos torna-se essencial. [...] Partir de uma igualdade numérica para elaborar problemas aditivos com uma operação é o caminho mais direto e mais natural para entrar na álgebra”.

Para Duval (2011b), a resolução de um problema pode exigir recurso a uma representação auxiliar condicional. Os enunciados dos problemas apresentados têm que possibilitar aos alunos o reconhecimento das operações pertinentes -e a maneira de possibilitar esses reconhecimentos não é uma questão gramática, sintática, de vocabulário.

Segundo o autor, a elaboração de problemas introduz a designação de relações entre números e operações descritivas ou funcionais; nesse caso, as letras podem assumir diferentes estatutos: de incógnita, de valor desconhecido ou de variável. De igual forma, a elaboração dos problemas também é importante, por permitir diferentes estruturas, tanto aditivas quanto multiplicativas - por essa razão, a implicação de utilizar letras com diferentes estatutos.

Hoje, Duval (2011b) acredita que, para ler um problema de matemática, é preciso cruzar duas informações de dimensões semânticas diferentes (terceira ideia). Exemplo: As bicicletas e os carros de um estacionamento somam 52 veículos e 168 rodas. Quantos carros e quantas bicicletas existem no estacionamento? Nesse problema, existem duas informações de dimensões semânticas diferentes que se cruzam. A informação não está 
no número de veículos, ou no número de rodas, nem no número de carros ou no número de bicicletas. A informação está no cruzamento. Os enunciados em língua natural são lidos linearmente e isso impede ocruzamento. Por essa razão, tabelas de dupla entrada são necessárias, pois a informação será encontrada na célula oriunda do cruzamento.

Segundo Duval et al., (2015, p.81), por vezes a dificuldade dos alunos em compreender os enunciados dos problemas reside no fato de que "as informações pertinentes em um enunciado de problema são sempre o resultado do cruzamento das designações de dois objetos que surgem de duas dimensões."Por essa razão, segundo o autor é necessário transformar o enunciado apresentado de forma linear em forma de texto, em uma forma bidimensional, como por exemplo em tabelas de dupla entrada.

A Tabela 1 caracteriza um exemplo.

Tabela 1: Tabela de dupla entrada

\begin{tabular}{llll}
\hline & Carros & Bicicletas & Total \\
\hline Quantidade de veículos & $\mathrm{X}$ & $\mathrm{y}$ & 52 \\
\hline Quantidade de rodas & $4 \mathrm{x}$ & $2 \mathrm{y}$ & 168 \\
\hline
\end{tabular}

As linhas e colunas cruzadas caracterizam células que carregam uma dupla informação (duas informações pertinentes). A comparação entre os elementos de duas linhas ou de duas colunas evidencia a "variabilidade redacional dos enunciados" (DUVAL et al., 2015, p. 83). Essa apresentação corresponde à forma de colocar em equação: $x+y=52$ e $4 x+2 y=168$ (leitura horizontal que corresponde ao enunciado do problema). Já uma leitura vertical, segundo o autor (p. 83), é um reagrupamento semântico de informações de mesma natureza (interfrase): x e 4x (quantidade de carros e quantidades de rodas dos carros), y e 2y (quantidade de bicicletas e quantidades de rodas das bicicletas). Segundo Duval et al. (2015, p. 83), essa abordagem “dos pontos de vista cognitivo e da aprendizagem[...] é importante, pois, encontramos o mesmo fenômeno com a compreensão dos enunciados de problemas que envolvem a pesquisa da quarta proporcional."

Segundo Duval (2011b), para resolver problemas reais não são as equações que são úteis, mas sim as fórmulas (quarta ideia). Numa fórmula, as letras codificam o termo genérico, dando lugar a medidas. Por exemplo: a área de um retângulo é igual ao produto da medida da base pela medida da altura: $\mathrm{A}=\mathrm{b} \times \mathrm{h}$.

Duval et al., (2015) aponta que é preciso lançar mão da operação de substituição de números por letras. Essa operação permite aplicar uma fórmula a dados que são 
resultantes de medidas. Fora da matemática, essa operação é usual (física, química, entre outras áreas), pois, segundo o autor, "a prática da matematização do conhecimento em todas as disciplinas científicas baseia-se nessa operação.” (p. 55). Essa operação é uma decodificação. No caso da utilização das fórmulas, as dificuldades são de natureza diferente. Duval et al., (2015, p. 16-17) cita como exemplo duas questões do Pisa de 2003. Em uma questão, valores de uma tabela expressos por meio de letras deveriam ser substituídos em uma fórmula dada. Em uma outra, uma fórmula apresentada continha um termo fracionário. Essas questões foram analisadas comparativamente em relação aos resultados apresentados por alunos de dois países diferentes (com sistemas educativos diferentes, sendo um deles considerado com melhor desempenho que o outro). Os resultados apontaram o mesmo desempenho nos dois países $(76 \%$ e $74 \%$ de sucesso na primeira questão, e $41 \%$ e $43 \%$ na segunda questão). Segundo o autor, a dificuldade se encontra não na presença do termo fracionário, mas sim na apresentação dos dados por meio de um enunciado. Ler os dados apresentados em uma tabela é mais fácil que interpretar um enunciado que explica uma fórmula. No ensino e aprendizagem da álgebra, devemos nos interrogar se as questões que dizem respeito à utilização de fórmulas são de fato questões de álgebra. Segundo o autor, "essa questão é fundamental, porque ela equivale a perguntar se o ensino da álgebra é necessário para aprender a aplicar fórmulas, forma da matemática, sobre os dados observados na realidade.” (p.16).

Por fim, de acordo com Duval (2011b), para a resolução de equações não são as letras que contam, mas a ocorrência das letras (quinta ideia). Segundo o autor, muitas pesquisas em álgebra que se valem de teorias semióticas buscam a diferença entre objeto e signo. Mas essa diferença não tem interesse para a álgebra quando olhamos para o terreno algébrico, mais especificamente para os cálculos que trabalham com a ocorrência das letras e não para a significação das letras. Duval (2011b) sugere que as coisas (ocorrência e significação das letras) não sejam feitas sucessivamente e sim em paralelo. A introdução das letras deve ser dissociada de toda atividade de resolução de problemas. Ela deve ser associada logo de entrada à designação funcional. A razão por que dissociar: as letras são introduzidas como incógnitas e isso faz criar uma associação durável entre uma letra e um número. O estatuto de letra co-variável termina e $90 \%$ dos alunos entendem que o estatuto da letra é variável. A introdução das letras deve obedecer à função de condensação, de que uma letra está no lugar de uma lista aberta. Para cumprir a designação funcional, é necessário não somente uma lista aberta, mas duas. Se isso não for feito, os alunos não passarão de tentativas numéricas. Como por exemplo "encontrar 
dois números sucessivos cuja soma é 121, estabelecer uma equação e resolvê-la". Primeiro os alunos trabalham com a calculadora e podem pegar dois números que não são sucessivos e cuja soma está longe de ser 121. Procedendo dessa maneira, encontram os números 60 e 61. Esse modo de agir não deve ser incentivado. Devemos levar os alunos a utilizar a forma $\mathrm{x}+\mathrm{x}+1=121$. Isso mostra que o problema não está na letra, mas na designação funcional. Devemos levar os alunos a trabalhar conjuntamente sobre a comparação das duas listas em paralelo. Trata-se de uma atividade de observação. Os alunos começam a escrever as duas listas e, em determinado momento, eles tomam consciência de que estão escrevendo a mesma coisa, pois estão diante de um problema de designação. Quando eles pensam de que forma podem parar, encontram-se diante de um problema de condensação. Ele troca o registro de partida pelo registro de chegada. É necessário variar o registro de entrada para que haja a atividade de redesignação. Essa proposta é anterior ao ensino das equações, sendo paralela à elaboração de problemas e ao uso de fórmulas. Em seguida, devemos levá-los a adquirir os mecanismos de aplicação matemática em situações reais, e a criarem os problemas.

De acordo com Duval et al., (2015), existe uma ruptura semiótica cognitiva entre colocar em equação e resolver essa equação, o que envolve transformações dessa equação (tratamento). No momento em que colocamos em forma de equação os elementos de duas listas que se relacionam, aparecem as letras para designar tais relações. Nesse sentido, as letras não são portadoras de sentido e referência, como são as palavras. As letras têm referência, mas não tem significação própria; nisso reside, segundo o autor, a sua estranheza. Quando realizamos um tratamento nas sentenças que envolvem letras, não olhamos as letras e sim a sua ocorrência. Isso significa voltar o olhar para as diferentes ocorrências de uma letra nessas sentenças, e para sua mudança de posição no momento de organizações operatórias dos membros da equação. No exemplo anterior, temos a equação $\mathrm{x}+\mathrm{x}+1=121$, que exigirá reorganizações operatórias do tipo: $2 \mathrm{x}+1=1 \rightarrow 2 \mathrm{x}$ $+1-1=121-1$ (princípio aditivo) $\rightarrow 2 \mathrm{x}=120 \rightarrow 2 \mathrm{x} / 2=120 / 2$ (princípio multiplicativo) $\rightarrow \mathrm{x}=60$.

Em virtude desse ponto de vista apontado por Duval (2011b) em relação ao ensino da álgebra, outras questões emergem e devem ser objeto de reflexões. Duval (2011b) nos apresenta algumas dessas questões e defende que elas devem preceder o ensino da álgebra. Essas questões compreendem seis interrogações cada uma, com sua lógica própria, e dizem respeito ao ensinar e ao aprender. Em se tratando do ensinar, são quatro questionamentos: Quais objetivos do ensino? Qual a decomposição do programa de 
álgebra em elementos de base (esses são de natureza institucional)? Que atividades devem ser propostas para atender esses objetivos (pelos manuais, pelo professor, nas pesquisas pelos pesquisadores)? A partir qual ponto de vista e como será feita a análise, isto é, em relação à natureza dos erros ou dos fatores que conduzem ao erro (esses se referem ao ensino e ao professor)?

De acordo com Duval (2011b), a organização da álgebra para o ensino, ao longo da vida escolar dos alunos, pode ser pensada segundo dois pontos de vista, opostos e incompatíveis: o ponto de vista matemático e o ponto de vista cognitivo. O que deve ser considerado, seja qual for a opção, é se haverá consequências para a formação dos professores e para as pesquisas.

\section{Considerações finais}

Para entender o ponto de vista cognitivo defendido por Raymond Duval para o ensino e a aprendizagem da álgebra, foi necessário um estudo que permitisse, em primeiro lugar, tanto explicitar a dimensão semio-cognitiva subjacente ao pensamento matemático, como evidenciar a face oculta e a face exposta da matemática. Em relação à dimensão semio-cognitiva, o estudo focou nas funções meta-discursivas e nas funções discursivas necessárias e essenciais para o desenvolvimento de uma atividade matemática visando a aprendizagem. O desenvolvimento da capacidade de designar evidencia a importância da função discursiva de designação e suas operações cognitivas de designação pura, categorização, determinação e descrição. Várias atividades podem ser elaboradas para contribuir com a construção da capacidade de designar, segundo Duval (2004), para a aprendizagem da álgebra. A designação de relações entre números e operações aritméticas pode contar com a língua natural, com a linguagem algébrica e com a linguagem gráfica. A designação é uma função dos registros discursivos (DUVAL, 2004) e só pode ser realizada por meio de suas operações cognitivas: designação pura, categorização simples, descrição e determinação de objetos por meio de léxicos associativos ou sistemáticos. Essas atividades podem, ao mesmo tempo, compreender as cinco ideias propostas por Duval (2011a) para a aprendizagem da álgebra segundo um ponto de vista cognitivo. Os registros discursivos irão exigir o cumprimento das funções discursivas, as quais exigem, por sua vez, as capacidades de observar padrões de regularidade expressos por meio de relações entre números articulados por operações aritméticas. Além disso, é necessário explicitar esses padrões com a utilização de sistemas 
semióticos discursivos (língua natural e linguagem algébrica), e generalizar esses padrões sinteticamente. Essas ações vão exigir operações cognitivas, visto que mobilizam léxicos sistemáticos e associativos para representar as letras e os números presentes nas relações; também mobilizam ações voltadas para compor enunciados (função apofântica) e validálos do ponto de vista lógico, social ou epistêmico; mobilizam ações para expandir os discursos por meio da acumulação de informações ou substituições (função de expansão discursiva); mobilizam ações para representar leis ou propriedades validadas na comunidade científica (função de reflexividade).

O estudo desenvolvido aqui permitiu evidenciar a importância da função de designação dentre as funções discursivas, isto é, de uma semiosfera do designar. Ao mesmo tempo, permite a valorização da face oculta da matemática, para dar conta do ponto de vista cognitivo proposto por Raymond Duval para um ensino de álgebra voltado para o desenvolvimento do pensamento algébrico e de uma aprendizagem efetiva e significativa de álgebra.

\section{Referências}

DUVAL, R. Semiosis y pensamiento humano: registros semióticos y aprendizajesintelectuales. Santiago de Cali: Peter Lang, 2004.

DUVAL, R. Ver e ensinar a matemática de outra forma: entrar no modo matemático de pensar os registros de representações semióticas. Org. Tânia M. M. Campos. Trad. Marlene Alves Dias. São Paulo: Proem Editora, 2011a.

DUVAL, R. Deux regards opposes sur les points critiques sur l'enseignement de l'algébre au collège (11-15 ans). Palestra proferida no Programa de Pós Graduação em Educação Matemática da Universidade Federal de Mato Grosso em 2011b.

DUVAL, R. Raymond Duval e a teoria dos registros de representação semiótica. Revista Paranaense de Educação Matemática - RPEM, Campo Mourão, v. 2, n. 3. p. 10-34, 2013.

DUVAL, R.; CAMPOS, T. M. M.; BARROS, L. G. X.; DIAS, M. A. Ver e ensinar a matemática de outra forma: introduzir a álgebra no ensino: qual o objetivo e como fazer isso.org. Tânia M. M. Campos. 1ed. São Paulo: PROEM, 2015.

FREGE, G. Écritslogiques et philosophiques. Tradução de Claude Imbert. Paris: Seuil, 1971.

LEMES, N. dos S.; CEDRO, W. L. Professores de matemática em atividade de ensino de álgebra: apropriações da teoria histórico-cultural. Revista Portuguesa de Educação, Braga, v. 28, n. 2, p. 133-154, jun. 2015.

LOTMAN, Y. M. The universe of the mind: a semiotic theory of culture. Trad. Ann Shukman. Londres: I. B. Tauris \& Co. LTD, 1990.

MERRELL, F. IúriLótman, C. S. Peirce e semiose cultural. Galáxia, São Paulo (PUC/SP), n. 5, p. 163-185, abr. 2003. 
MORETTI, M. T. A Translação como recurso no esboço de curvas por meio da interpretação global de propriedades figurais. In: MACHADO, Silvia D.A. de. (Org.). Aprendizagem em matemática: registros de representação semiótica. Campinas: Papirus, 2003, p. 149-160.

PONTE, J. P.; BRANCO, N.; MATOS, A. Álgebra no ensino básico. Ministério da Educação: Direção Geral de Desenvolvimento e Inovação Curricular (DGDIC), 2009.

RIBEIRO, A. J. Álgebra e seu ensino: dando eco às múltiplas "vozes" da educação básica. REnCiMa, São Paulo, Edição Especial: Educação Matemática, v.7, n.4, p. 1-14, 2016.

RIBEIRO, A. J.; CURY, H. N. Álgebra para a formação do professor. Belo Horizonte: Autêntica Editora, 2015.

SAUSSURE, F. de. Curso de linguística geral. Tradução de A. Chelini, J. P. Paes, I. Blikstein. São Paulo: Cultrix, 2008.

Recebido em: 15 de fevereiro de 2018.

Aceito em: 06 de abril de 2018. 